$$
\text { "ratusinski" — 2007/8/10 — 11:06 — page } 67 \text { — \#1 }
$$

\title{
The role of computer in the process of solving of mathematical problems (results of research)
}

\author{
HENRYK KĄKOL and TADEUSz RATUsiński
}

Abstract. We would like to present results of an almost two years investigations about the role computer in the process of solving of mathematical problems. In these investigations took part 35 students of the secondary school (generalists) in the age 17-19 years. Each of these students solved following problem:

Find all values of the parameter $m$ so that the function

$$
f(x)=|m x+1|-|2 x-m| \text { is: }
$$

a) bounded,

b) bounded only from the bottom,

c) bounded only from above,

first without a computer and next with a special computer program. We would like to show results of these researches.

Key words and phrases: investigating and problem solving, technological tools, educational research and planning (upper secondary school), comprehensive works on instructional materials, educational technology and media research, mappings and functions (upper secondary school).

ZDM Subject Classification: D50, U70, B14, U10, I24.

\section{Introduction}

We have been living in a world that makes us more and more addicted to the surrounding Information Technology. Computers have already been used in 


$$
\text { "ratusinski" - 2007/8/10 - 11:06 — page } 68-\# 2
$$

every field of life. Their role in education has also become crucial. Teaching of mathematics with the use of computers is the subject of many discussions conducted both by teachers and educators. There has been some research on various problems connected with functioning of computers in the teaching process. Our research concentrated on the discovery of the role they have in the process of task- problem solving.

The research findings offer interesting remarks that are sometimes in opposition to the commonly accepted views. There is no doubt that the computer is a grand tool that has unquestionable advantages, but it should be used with caution as when misused it can do more harm than it can bring profits.

The process of teaching mathematics is extremely complex and difficult. On the one hand, we have mathematical contents, specific in their character, very often abstract, static and totally unpopular with the majority of pupils. On the other hand, we have pupils of unique characters looking on the world and the nature of mathematics in a specific way. But there is also a teacher who is often inclined to use a way of teaching where he is just a resource of knowledge trying to transmit or direct it to the minds of pupils.

In modern teaching, the process of teaching mathematics and the teacher's role in this process is understood in a completely different way. The teacher should be the organiser of the process of learning mathematics by pupils. He should organise it in such a way as to link the presentation of mathematical content with the pupil's learning independence. He has to accustom the pupils to reading mathematical texts with understanding (descriptions, explanations, definitions, statements, proofs etc.), to encourage them to use different sources of mathematical knowledge (magazines, popular science books, computer programmes, the internet, etc.), to create such mathematical activities that will become helpful in their adult life in the future $[7,15]$.

If we add to the above the fact that the teacher of mathematics has to be a tutor as well and that he ought to inspire and develop the interests of his pupils, that apart from deep, content related knowledge he should be acquainted with psychology, especially developmental psychology, that he should understand the psychological processes that accompany the formation of notions - it becomes apparent that the organization of the process of teaching mathematics is extremely difficult.

In the process of teaching mathematics one can distinguish, with a considerable simplification, four components:

- Forming of mathematical terms 


$$
\text { "ratusinski" — 2007/8/10 - 11:06 — page } 69-\# 3
$$

- Task solving

- Mathematical reasoning

- Establishing mathematical language [3].

One of the most important parts of the process of teaching is task solving. Tasks are the means of consolidation of acquired knowledge, they create the ability of their application, help to evaluate the pupil's progress and results of teaching (oral and written examinations and tests); with their help mathematical terms are designed and defined, mathematical deliberation is taught, the use of mathematics is shown and they are also the aid of shaping the imagination. They are an important activating factor, often stimulating the development of pupils' interests.

Various types of problems can be distinguished among those that are solved when teaching mathematics. In school teaching the most frequent are [7]:

- Tasks that require pupils' calculation skills, knowledge of arithmetic rules, mental reckoning. Thus they are used to consolidate knowledge, and make given operations mechanical. They are solved with little creative engagement of the pupil and with little use of theory.

- Common use of theory- solving of those tasks need more diverse activities, independence, various elements of theory and, in particular, the application of definitions and theorems. When solving such problems you work following a pattern, in accordance with a certain known algorithm.

- Problems - tasks that cannot be worked out at a given level of teaching without certain ingeniousness, without a small amount of mathematical imagination, because for their explanation neither simple knowledge nor technical skill or experience in typical task solving is enough.

Problems play a specific role among the tasks and they are described by Z . Krygowska [7] as follows:

Tasks which cannot be solved without a dose of ingeniousness on a given level of education, without a tiny bit of mathematical imagination, because to solve them, neither knowledge is sufficient, nor technical skill, not even experience in solving typical tasks.

What is the role of such tasks in teaching mathematics? Why do we solve such tasks? Why does the teacher use them in school practise? The answer seems to be obvious. How the researches and school practice in Poland show $([1,2,3,5,6,11,12,13,14])$ they allow the teacher to discover open-minded pupils, with an uncommon approach to solving tasks, with a kind of brilliance in finding a solution, in other words, they allow the teacher to find mathematically 


$$
\text { "ratusinski" — 2007/8/10 - 11:06 - page } 70-\# 4
$$

talented pupils. When solving such tasks, pupils sometimes become interested in mathematics, they change their emotional attitude towards it. However, the most important advantage of problems is that they make a perfect base for developing and forming mathematical activities. When solving them, pupils learn to generalise, they use analogies and become engaged in mathematical deliberations.

\section{Data}

The first attempts of using the computer in problems solving showed a lot of doubts, questions and problems $([1,2,3,5,6,11,12])$. Here are some of them:

- What types of problems allow the use of the computer?

- What is the role of the computer in problem solving?

- What are the advantages and disadvantages of using the computer in problem solving?

- How can the computer be useful to pupils who are not interested in mathematics and in problems solving?

- Can the computer be useful to pupils who are interested in mathematics and in problems solving and what are the benefits of its use?

To be able to answer this question and find, at least partially, answers to the previously asked questions some research has been done. We used followed an example [4].

Find all values of the parameter $m$ so that the function

$$
f(x)=|m x+1|-|2 x-m| \text { is: }
$$

a) bounded,

b) bounded only from the bottom,

c) bounded only from above,

It was conducted individually (the researcher and the pupil) and was divided into seven phases.

- Phase 1 consisted in gathering all possible information about a given pupil in an interview with him, his parents and teachers. 


$$
\text { "ratusinski" — 2007/8/10 — 11:06 — page } 71 \text { — \#5 }
$$

- In phase 2 the pupil was asked to fill in a special individual questionnaire, the aim of which was to learn more about the personality of the pupil, in particular his school fears, his attitude to mathematics, computers and ICT (Figure 1).

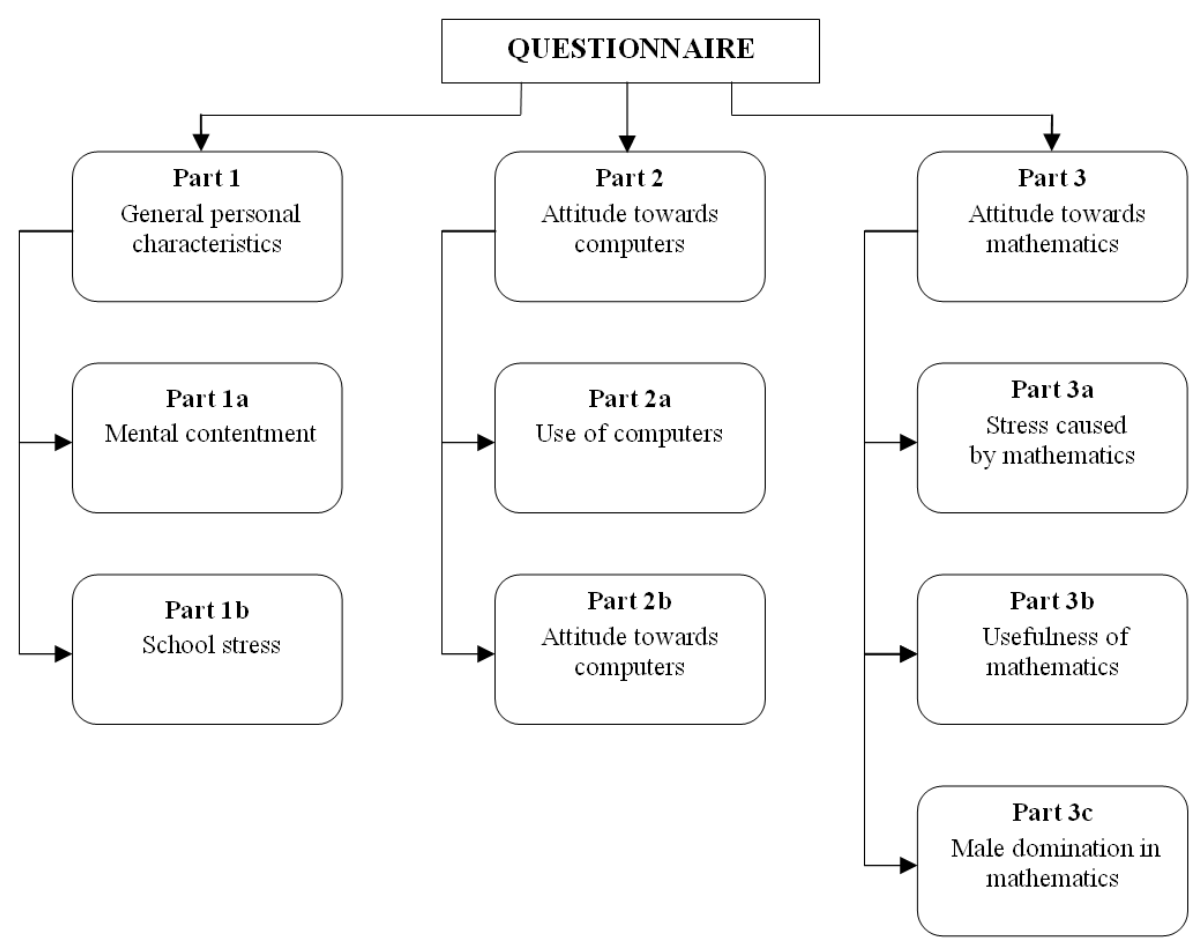

Figure 1

Pupils had to answer for example such question from part 3: I feel emptiness in the head and I'm not be able to rationally thinking, when I work over math's and they had to put $X$ mark in one of boxes:

$\square$ I entirely agree

$\square$ I partly agree

$\square$ I'm not sure

$\square$ I partly not agree

$\square$ I entirely not agree 


$$
\text { "ratusinski" — 2007/8/10 - 11:06 - page } 72 \text { - \#6 }
$$

- Phase 3 was an attempt to solve the problem without the aid of the computer. The pupil tried to work out the problem having at his disposal only mathematical tables, a writing kit and his knowledge. He could use a specially prepared set of definitions and examples of a bounded function, function bounded from the bottom, and function bounded from above. Picture number 2 shows an example of such a solution (Figure 2).

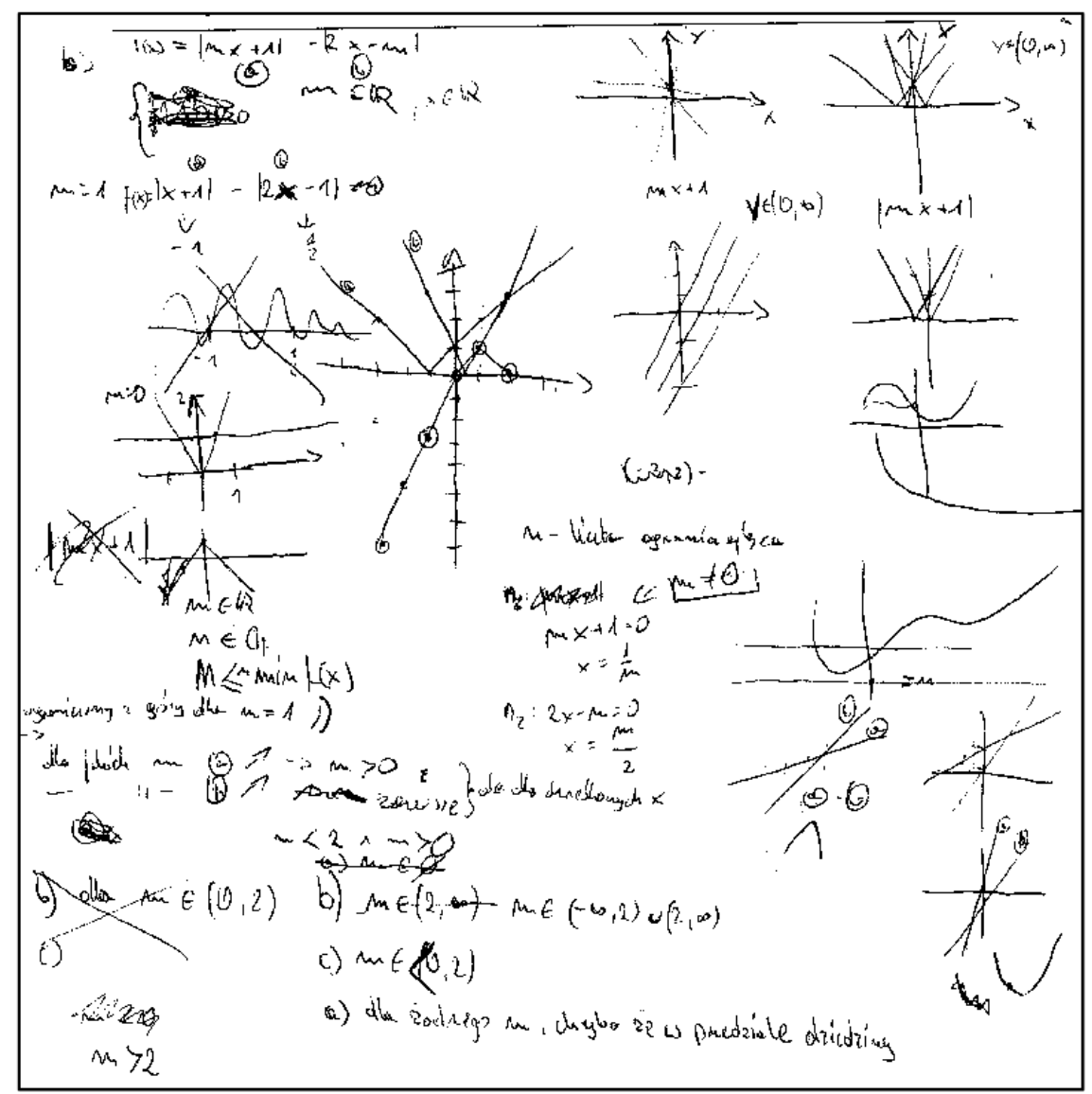

Figure 2

As you can see pupil tried to draw some graphs, observe them. There are a lot of erasures on this paper, both on drawings and in calculations. We can hardly uncover the way he conduct from this paper. 


$$
\text { "ratusinski" — 2007/8/10 - 11:06 - page } 73-\# 7
$$

- Phase 4 was a discussion, the aim of which was the explanation of reasons of probable failure and some problems the pupil met when solving the task. The following questions were asked:

- Was the problem interesting for you?

- Did you understand the instructions of the task?

- Are you acquainted with all the notions appearing in the content of the task?

- What in your opinion contributed to your success (your failure)?

These questions could obviously be modified according to the way of solving the problem by the pupil.

- In phase 5 the pupil got acquainted with the program Graphs of the Function (Figure 3) he later used to solve the discussed task.

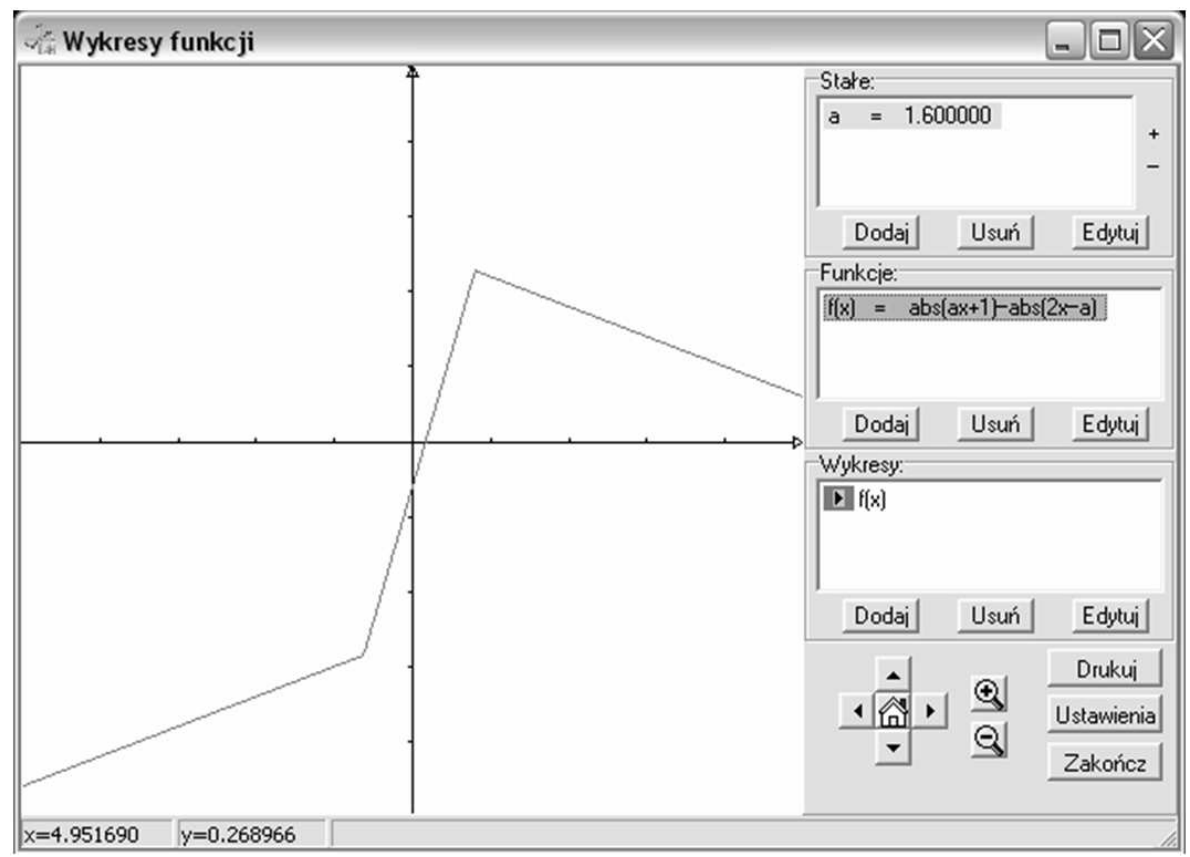

Figure 3

This program is freeware. It can be used in the different way than CAS programs. How you can see in the right upper horn of the drawing (Figure 3) 


$$
\text { "ratusinski" — 2007/8/10 — 11:06 - page } 74 \text { — } 8
$$

there are two button + and - which one can easily change the value of the parameter $a$. Pupil just press them and observe what happen with graph? It's different idea of proceeding. We do not observe static graphs created by the program, but we order to change the graph dynamically in interactive way.

- In phase 6 the pupil got access to a computer equipped with the above mentioned program and had another attempt to solve the problem. The whole process was registered with the aid of a special computer program. Pupils knew that their work would be recorded (and they expressed on this agreement), but they did not know technical details. The program recording worked in the background imperceptibly. The recording became the basis of a film that was used for the analysis of the pupil's work.

- The last phase 7 was another talk with the pupil, the purpose of which was to find answers to the following questions:

- Are you convinced that the answer is correct?

- Do you feel you need to justify the correctness of the answer?

This kind of research has been applied to 35 pupils of the sixth form (18 plus). The results are as follows (Figure 4).

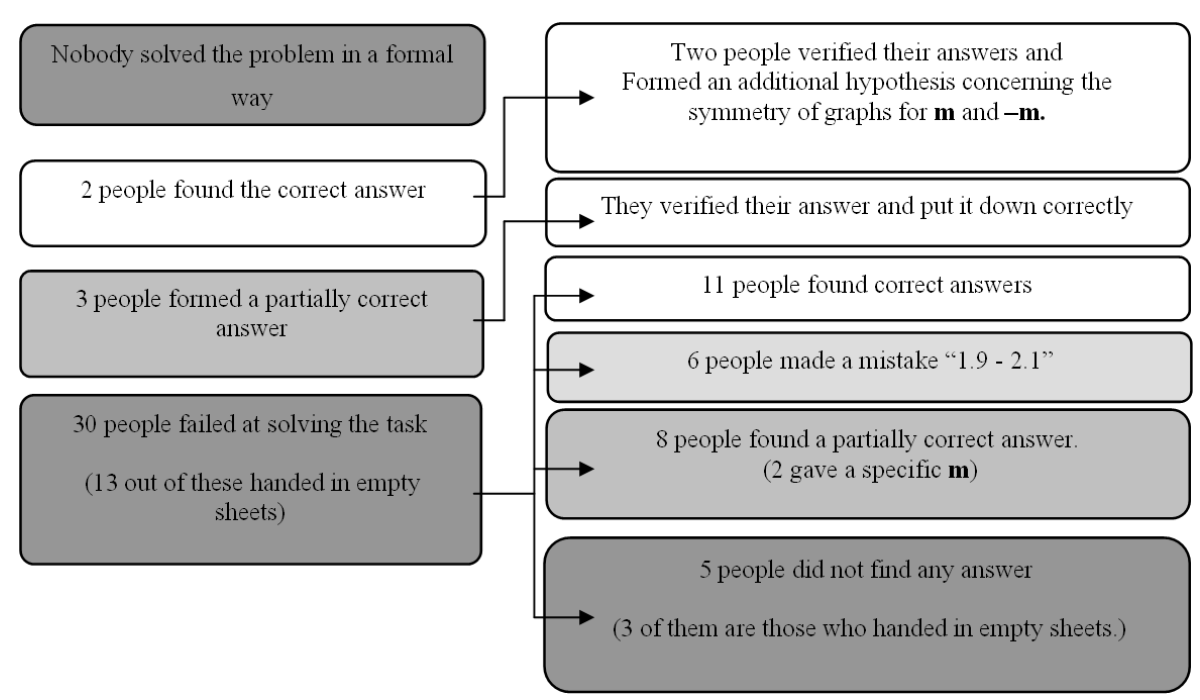

Figure 4 


$$
\text { "ratusinski" — 2007/8/10 — 11:06 — page } 75 \text { — \#9 }
$$

In the left column you can see results after phase 3 , in the right one results after phase 5 . The arrows show progress of pupils, for example: 30 people failed at solving the task in phase 3 (left column), in phase $5-11$ of them found correct answers, 6 of them make mistake "1.9-2.1", 8 of them found partially correct answer, rest 5 pupils did not find any answer.

The mistake " $1.9-2.1$ " is specific error, pupils wrote down answers to specific Questions in the form of the interval $(-1.9 ; 2.1)$, whereas the correct answer was $(-2 ; 2)$. It was because they had observing changes of the graph with 0.1 steps (technical condition of the program which can be altered by the user).

\section{Analysis}

Figure 5 shows the results of the pupils' work solving the problem in the traditional way.

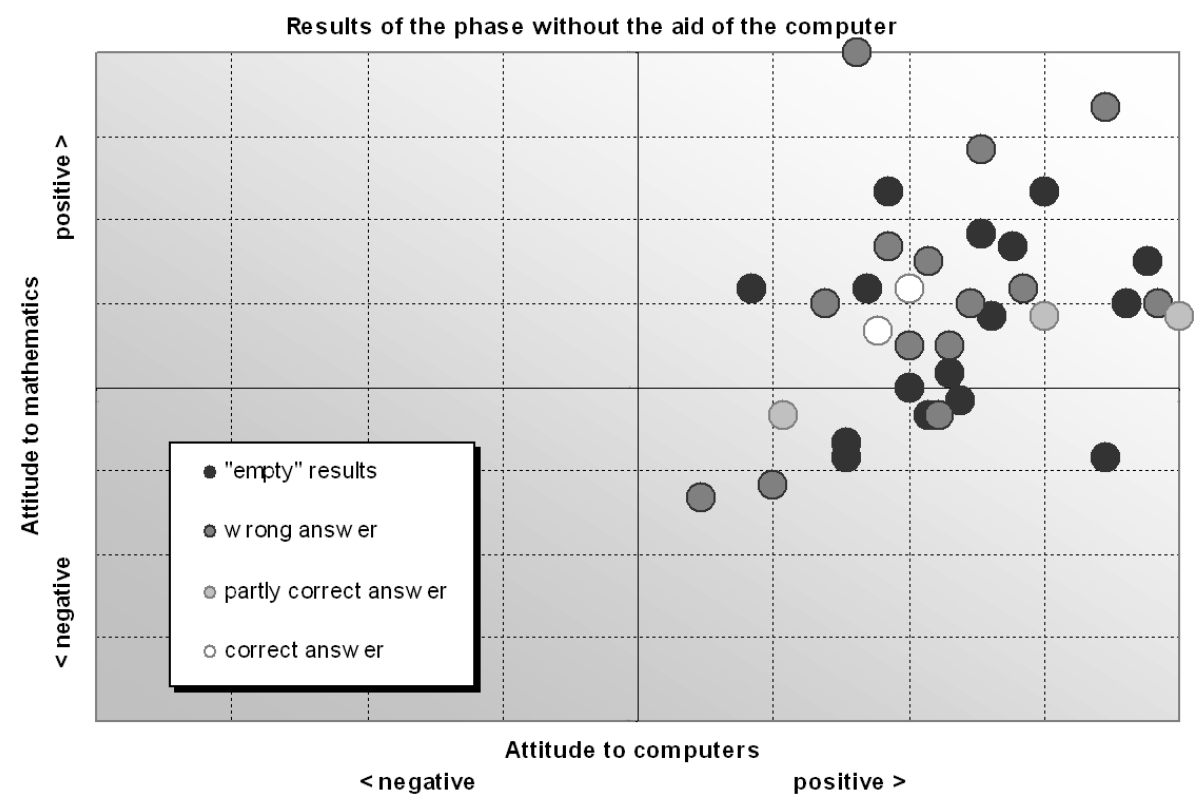

Figure 5 


$$
\text { "ratusinski" — 2007/8/10 - 11:06 - page } 76 \text { - \#10 }
$$

The results of the pupils' work solving the same problem with a computer programme is shown in Figure 6.

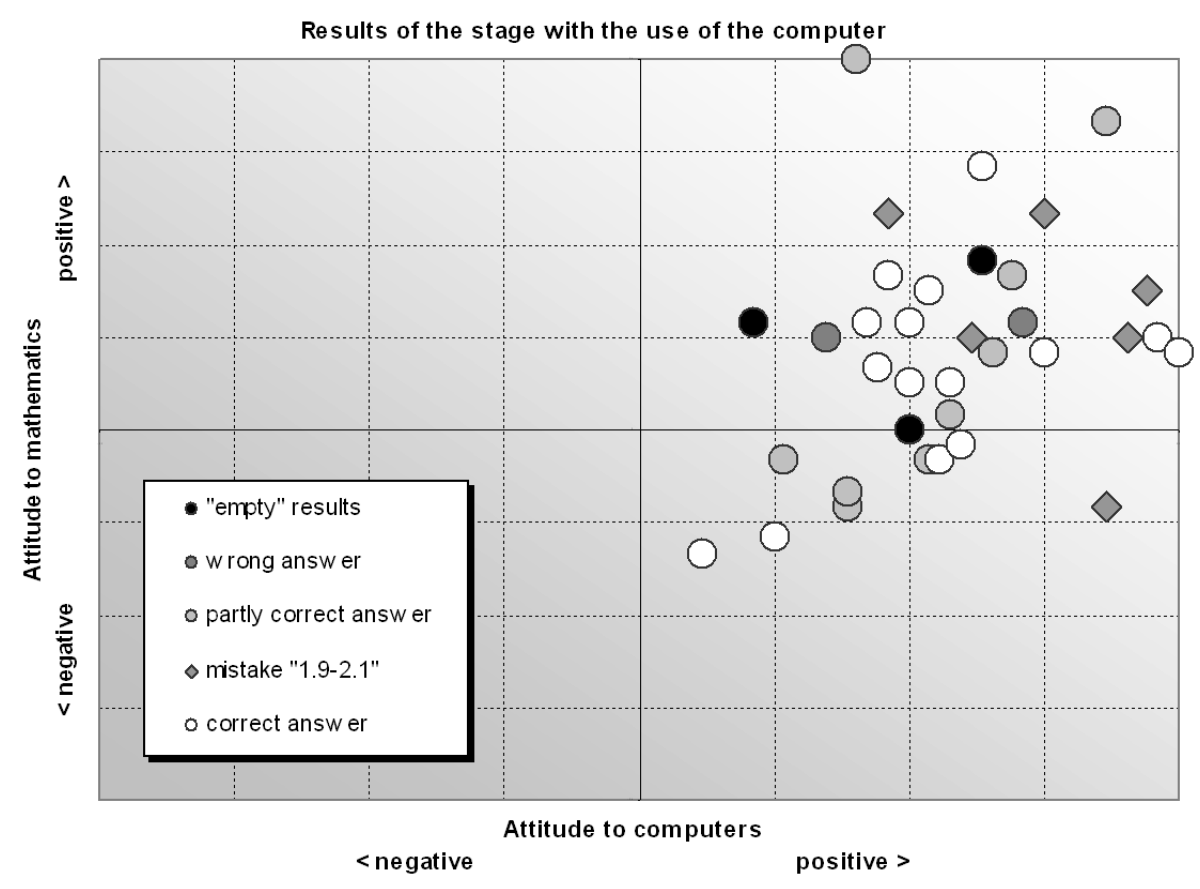

Figure 6

Both of the presented results of the pupils' work are based on their attitude towards mathematics and the ICT (this is adequate to results of individual questionnaire). Each dot represents one pupil and its colour corresponds with the result.

The conventional system of coordinates allows us to describe the position of each dot as the pupil's attitude to the researched feature. Thus, for example, the conventional horizontal axis shows the attitude to ICT (the more the dot is shifted to the right the more positive is the pupil's attitude to computers, the more it is shifted to the left, the more negative it is.)

The perpendicular axis shows in a similar way, the attitude to mathematicsthe more positive the attitude, the further up the dot will be, the more negative the attitude, the further down the dot. The axes represent a neutral attitude. Let us now look at both drawings. 


$$
\text { "ratusinski" — 2007/8/10 - 11:06 — page } 77 \text { — \#11 }
$$

The analysis of drawing 5 and also the originals of pupils works and recorded films allows us to form several conclusions relating to the pupils' work on the considered task without the help of the computer. Here they are:

- It is easy to notice that none of the pupils declared a negative attitude towards computers. However, there were some who did not hide their reluctance to mathematics. As it seems, the majority of pupils prefer ICT to mathematics.

- Those pupils who found the correct answers at this stage (they are represented by white dots on the graph) did no regard themselves as particularly keen on both subjects.

- The next interesting conclusion can be drawn in relation to pupils who found partial answers (light gray dots) - they belong to people who definitely prefer ICT to mathematics.

- However, it is difficult to form clear conclusions concerning pupils who did not solve the problem, handing in empty sheets or giving the incorrect answer. There are representatives of all attitudes to both subjects in this group. There are people with an exceptionally favourable attitude towards mathematics, some declaring reluctance to it, some willingly accepting computers as well as pupils prejudiced against them.

- Additionally, we can notice that the majority of pupils who expressed their reluctance to mathematics left empty sheets (black colour of dots).

- There are no satisfactory conclusions or a visible dependence between the results achieved by and their attitude to mathematics and ICT. Now let us look at the next drawing (Figure 6) the analysis of which will allow us to draw conclusions concerning the pupils' work with computers.

- Pupils who made the mistake "1.9 - 2.1" (they wrote down answers to specific Questions in the form of the interval $(-1.9 ; 2.1)$, whereas the correct answer was $(-2 ; 2))$, confirm in the questionnaire their positive attitude to computers. It would confirm the presumption that the reason of the mistake is the excessive confidence the pupils have in computers.

- The pupils who failed to find even a partly correct solution while working with the computer (black and dark gray dots in Figure 6) failed to do so in the previous stage of work as well. (The same colours of dots in Figure 5). It shows that there is no positive influence of the presence of the computer on their efficiency in solving the task.

- It is surprising that among the "stronger" pupils (represented with dots which are situated in the right upper part of the first quarter on the graph on 


$$
\text { "ratusinski" — 2007/8/10 - 11:06 — page } 78 \text { — \#12 }
$$

Figure 6) we can find both pupils who found the correct solution and those who handed in empty sheets. Every kind of solution finds its representative in this group (in this part of the graph we can notice all the styles of dots).

We can also notice in the graph that the pupils representing the "below the average" attitude to mathematics (pupils "bad" at mathematics) in the prevailing majority found at least a partial solution to this problem. Half of them found the correct answer using the computer.

\section{Conclusions}

The analysis of the collected material enabled to formulate partial answers to some of the previously asked questions, and showed other, interesting facts. Here they are.

- There is no doubt that a well-chosen computer program, serving a given problem can contribute to finding answers to questions raised in this problem.

- Most pupils found the correct answer to questions formed in this task. However, there were some pupils who could not make use of the computer in this respect.

- The computer, which allowed pupils to find the correct answer, was so convincing to them that they did not need to justify the perceived remarks $[9,10]$.

- The use of the computer allowed the weak pupils to overcome barriers consisting in the lack of understanding of the previously learned topics. The pupil can still work on a task, and as a result, acquire new experiences and knowledge. The gaps in their knowledge do not become bigger. The computer becomes a kind of "scaffolding" over the not perfectly acquired abilities they can refer to later, in an appropriate moment [8].

- The computer can create a new educational situation where the pupil overcomes the stress (fears) caused by their inability to solve the problem.

- The computer and the new situation increase the pupils' interest in the problem and, at the same time, allow a better understanding of it and as a result let them find answers to the questions raised in the problem.

- The computer can help in understanding mathematical concepts that appear in the task presenting for example, pictures of these concepts.

- The computer can check the results acquired during the task solving. 


$$
\text { "ratusinski" — 2007/8/10 - 11:06 — page } 79-\# 13
$$

- The computer can suggest a method of solving the problem, although it is essential to be a good observer and to draw conclusions.

- The use of the computer reverses the situation of the person solving the problem- they do not look for something unknown but justify a given hypothesis.

The researched pupils had not continuous contact with the computer during their mathematical education. One can suppose that if the computer had become a didactic aid for the pupils they would have had a different approach to solving the problem, and at the same time would have presented different solutions. This remark depicts an alternative path of research into thisfield.

\section{References}

[1] H. Kąkol, Mathematical tasks and computer (1), Matematyka i Komputery 18 (2004).

[2] H. Kąkol, Mathematical tasks and computer (2), Matematyka i Komputery 19 (2004).

[3] H. Kąkol, Problem-based teaching of mathematics with computer, Matematyka $i$ Komputery 1 (2000).

[4] H. Kakol, Z. Powazka, Notion of the function, part 2, Wydawnictwo "Dla szkoty", Bielsko-Biała (1998).

[5] H. Kąkol, T. Ratusiński, The part of the computer in solving mathematical tasks, Dydaktyka Matematyki 26 (2004), 119-142.

[6] H. Kąkol, T. Ratusiński, The role of computer in process of solving of mathematical problems (the results of investigation), Proceeding of the $6^{\text {th }}$ International Conference on Technology in Mathematics Teaching, University of Thessaly, Volos, Greece (2003), 53-59.

[7] A. Z. Krygowska, Zarys dydaktyki matematyki (The didactics of mathematics), part 3, Wydawnictwa Szkolne i Pedagogiczne, Warszawa (1977) (in Polish).

[8] B. Kutzler, The Algebraic Calculator as a Pedagogical Tool for Teaching Mathematics, 1999, www.kutzler.com/bk/a-pt/ped-tool.html\#scaffolding.

[9] R. Pawlak, Do calculators and computers lead to the formation of epistemological obstacles?, Nauczyciele i matematyka 40 (2001).

[10] A. Sierpińska, Notion of epistemological obstacle in the teaching of mathematics, Dydaktyka Matematyki 8 (1998), 103-153.

[11] T. Ratusiński, How a computer initiated an extension of a problem, Acta Univ. Purkynianae 42 Studia Mathematica: Czech-Polish mathematical School 1999 (1999), 87-97. 


$$
\text { "ratusinski" — 2007/8/10 - 11:06 - page } 80-\# 14
$$

80 H. Kąkol, T. Ratusiński : The role of computer in the process of solving of math. problems

[12] T. Ratusiński, The part of computer in the process of solving mathematical tasks, Dydaktyka Matematyki 25 (2003), 262-269.

[13] T. Ratusiński, Part of the computer in uncovering mathematical statements, Matematyka i Komputery 4 (2000).

[14] T. Ratusiński, The role of the computer in discovering mathematical theorems, Acta Univ. Purkynianae 72 Studia Mathematica: Czech-Polish mathematical School 2001 (2001), 164-169.

[15] S. Turnau, Wyktady o nauczaniu matematyki (Lectures about the teaching of mathematics), Wydawnictwo Naukowe PWN, Warszawa, 1990 (in Polish).

PROF. HENRYK KAKOL

DR TADEUSZ RATUSIŃSKI

INSTITUTE OF MATHEMATICS

PEDAGOGICAL UNIVERSITY

UL. PODCHORĄŻYCH 2

30-084 CRACOW

POLAND

E-mail: henkakol@ap.krakow.pl

E-mail: ratusita@ap.krakow.pl

(Received March, 2006) 